\title{
Erratum to: Prognostic value of myocardium perfusion imaging with a new reconstruction algorithm
}

Ronaldo Lima, MD, PhD, ${ }^{\mathrm{a}, \mathrm{b}}$ Andrea De Lorenzo, MD, PhD, ${ }^{\mathrm{a}, \mathrm{c}}$ Gabriel Camargo, MD, ${ }^{\mathrm{b}}$ Gabriel Oliveira, BS, ${ }^{\mathrm{a}}$ Thiago Reis, BS, ${ }^{\mathrm{a}}$ Thais Peclat, BS, ${ }^{\mathrm{a}}$ Tamara Rothstein, $\mathrm{PhD},{ }^{\mathrm{b}}$ and Ilan Gottlieb, MD, PhD, ${ }^{\mathrm{b}, \mathrm{c}}$

a Universidade Federal do Rio de Janeiro, Cardiology, Rio de Janeiro, Brazil

b Clinica de Diagnostico por Imagem, Cardiologia Nuclear, Rio de Janeiro, Brazil

${ }^{c}$ National Institute of Cardiology, Cardiac Imaging, Rio de Janeiro, Brazil

doi: $10.1007 / \mathrm{s} 12350-013-9840-x$

\section{ERRATUM TO: J NUCL CARDIOL} DOI 10.1007/S12350-013-9824-X

This article was published with the given name and family name of each author in reverse order. The erratum lists the author names in the correct ordergiven name followed by family name.

The online version of the original article can be found under doi:10.1007/s12350-013-9824-x.

Reprint requests: Ronaldo Lima, MD, PhD, Universidade Federal do Rio de Janeiro, Cardiology, Rio de Janeiro, Brazil; ronlima@ hotmail.com.

J Nucl Cardiol 2014;21:221.

$1071-3581 / \$ 34.00$

Copyright (c) 2013 American Society of Nuclear Cardiology. 